\title{
Comments on: Modified Pereira Suture as an Effective Option to Treat Postpartum Hemorrhage Due to Uterine Atony
}

\author{
Shigeki Matsubara10 \\ ${ }^{1}$ Department of Obstetrics and Gynecology, Jichi Medical University, \\ Shimotsuke, Japan \\ Rev Bras Ginecol Obstet 2019;41:206-208.
}

Dear Editor,

Moleiro et al ${ }^{1}$ reported that a modified Pereira uterine compression suture (UCS) achieved hemostasis in two patients with postpartum hemorrhage. In the original Pereira suture, multiple sutures were applied both longitudinally and transversally around the uterus, with threads not penetrating the uterine wall and thus not entering the uterine lumen. ${ }^{2,3}$ The procedure described by Moleiro et al was the combination of the B-Lynch and the Pereira sutures, and thus, they referred to it as the modified Pereira suture. I have some concerns and clarifications.

First, Moleiro et al ${ }^{1}$ stated that the "Pereira suture can be performed when there is no hysterotomy," and that this is a merit of the Pereira suture. However, Moleiro et al ${ }^{1}$ concomitantly used the B-Lynch suture, which requires hysterotomy. ${ }^{4}$ Actually, the requirement of hysterotomy is considered a pitfall of the B-Lynch suture. ${ }^{3,5}$ For the concomitant use with the Pereira suture, the Hyman suture (simple brace suture: simple B-Lynch suture $)^{6}$ may be better, since it does not require hysterotomy. ${ }^{3,6}$

Secondly, the rationale for the addition of the Pereira suture is unclear. Moleiro et $\mathrm{al}^{1}$ performed the B-Lynch suture first, followed by a transverse Pereira suture. B-Lynch or Hayman threads sometimes "slide out" laterally, failing to achieve hemostasis: ${ }^{3,6}$ we have devised the Matsubara-Yano (MY) UCS, which prevents the threads from sliding out. ${ }^{3,6}$ Although Moleiro et al ${ }^{1}$ did not mention this, the transverse Pereira suture may also prevent sliding out. On the other hand, UCSs should be simple, as long as hemostasis can be achieved. $^{3}$ Thus, there may be 2 scenarios: 1) The Pereira suture was added since the B-Lynch suture did not achieve hemostasis, or 2) the B-Lynch suture achieved hemostasis and the Pereira suture was added prophylactically to prevent the sliding out of the thread. Scenario 1) means the emergent

\footnotetext{
(1) Shigeki Matsubara's ORCID is https://orcid.org/0000-0003-4378221X.
}

Address for correspondence Shigeki Matsubara, MD, PhD, Department of Obstetrics and Gynecology, Jichi Medical University, 3311-1, Shimotsuke, Tochigi 329-0498, Japan, Shimotsuke 329-0498, Japan (e-mail: matsushi@jichi.ac.jp).

addition of the Pereira suture (emergent modified Pereira suture), whereas scenario 2) means the planned prophylactic addition of the Pereira suture (planned modified Pereira suture). I wish to know the fundamental concept of the modified Pereira suture.

I commend Moleiro et $\mathrm{al}^{1}$ for re-evaluating the Pereira UCS. To my knowledge, $\sim 30$ UCS have been hitherto reported. Of them, the B-Lynch, ${ }^{4}$ the Hayman, ${ }^{6}$ the Cho, ${ }^{7}$ and the $\mathrm{MY}^{3,5}$ sutures are cited in the Williams Obstetrics textbook, ${ }^{8}$ and these four sutures have been repeatedly reported, meaning that they were re-evaluated. However, other UCSs have been rarely re-evaluated: many researchers appear to be enthusiastic to establish new UCSs. Actually, a PubMed search retrieved only one report re-evaluating the Pereira suture. ${ }^{9}$ Moleiro et $\mathrm{al}^{1}$ have revived the Pereira suture, which should be commended. Now is the time to re-evaluate various UCSs. Such efforts may determine which UCS should be used according to individual situations.

Conflicts of Interest

The author has no conflicts of interest to declare.

\section{References}

1 Moleiro ML, Guedes-Martins L, Mendes A, Marques C, Braga J. Modified Pereira suture as an effective option to treat postpartum hemorrhage due to uterine atony. Rev Bras Ginecol Obstet 2018; 40(02):92-95. Doi: 10.1055/s-0037-1613690

2 Pereira A, Nunes F, Pedroso S, Saraiva J, Retto H, Meirinho M. Compressive uterine sutures to treat postpartum bleeding secondary to uterine atony. Obstet Gynecol 2005;106(03):569-572. Doi: 10.1097/01.AOG.0000168434.28222.d3

3 Matsubara S, Yano H, Ohkuchi A, Kuwata T, Usui R, Suzuki M. Uterine compression sutures for postpartum hemorrhage: an overview. Acta Obstet Gynecol Scand 2013;92(04):378-385. Doi: 10.1111/aogs.12077

4 B-Lynch C, Coker A, Lawal AH, Abu J, Cowen MJ. The B-Lynch surgical technique for the control of massive postpartum
DOI https://doi.org/ $10.1055 / \mathrm{s}-0039-1681111$. ISSN $0100-7203$.
Copyright ( 2019 by Thieme Revinter Publicações Ltda, Rio de Janeiro, Brazil

\section{License terms}

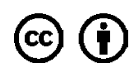


haemorrhage: an alternative to hysterectomy? Five cases reported. Br J Obstet Gynaecol 1997;104(03):372-375. Doi: 10.1111/j.1471-0528.1997.tb11471.x

5 Takahashi H, Baba Y, Usui R, et al. Matsubara-Yano suture: a simple uterine compression suture for postpartum hemorrhage during cesarean section. Arch Gynecol Obstet 2019;299(01): 113-121. Doi: 10.1007/s00404-018-4947-6

6 Hayman RG, Arulkumaran S, Steer PJ. Uterine compression sutures: surgical management of postpartum hemorrhage. Obstet Gynecol 2002;99(03):502-506. Doi: 10.1016/S0029-7844(01) 01643-X
7 Cho JH, Jun HS, Lee CN. Hemostatic suturing technique for uterine bleeding during cesarean delivery. Obstet Gynecol 2000;96(01): 129-131. Doi: 10.1016/S0029-7844(00)00852-8

8 Cunningham FG, Leveno KJ, Bloom SL, et al. Obstetrical hemorrhage. In: Cunningham FG, Leveno KJ, Bloom SL, eds. Williams obstetrics. $25^{\text {th }}$ ed. New York, NY: McGraw-Hill; 2018:735-802

9 Stein W, Hawighorst T, Emons G. [Surgical treatment of severe postpartum haemorrhage with uterine compression sutures as described by Pereira]. Z Geburtshilfe Neonatol 2008;212(01): 18-21. Doi: 10.1055/s-2008-1004687

\title{
Authors' Reply
}

\author{
Maria Lúcia Moleiro ${ }^{1} \odot$ Luís Guedes-Martins ${ }^{1} \quad$ Alexandrina Mendes ${ }^{1} \quad$ Cláudia Marques $^{1}$ Jorge Braga ${ }^{1}$
}

${ }^{1}$ Woman's and Reprodutive Medicine Department, Centro Materno Infantil do Norte, Centro Hospitalar Universitário do Porto, Porto, Portugal

\section{Dear Editor,}

The modification of the Pereira suture described by our team was performed during a cesarean section, when uterine atony was noted and was not responsive either to uterotonic drugs or to bimanual uterine massage. Given the success rates of uterine compression sutures (UCSs) described and the possibility of uterus preservation, they were the chosen method.

Since hysterotomy had already been performed, the BLynch suture was the first technique used. ${ }^{1}$ As the uterine atony persisted, the Pereira technique was chosen due to its characteristics: an even distribution of pressure around the uterus, due to the small bites at regular intervals in the uterine wall; not entering the uterine cavity, thus reducing the risk (at least theoretically) of uterine synechiae and infection; the ability to prevent the sliding out of the thread after uterus involution, reducing the risk of bowel and intestine entrapment. $^{2}$

The emergent need for hemorrhage control in cases of uterine atony limits the existence of quality evidence stating superiority amongst UCS techniques. Nevertheless, previous reviews report success rates $>75 \%$ (some of them $>90 \%$ ), regardless of technique. ${ }^{3-6}$ In these works, variations of the B-Lynch suture were reported as being as effective or even superior to the original technique. However, the chosen technique may not be the only variable contributing to the disparity of results, and the timing in which uterine compression sutures are applied, as well as surgeons' experience, is of vital importance. ${ }^{3,6-12}$

The two cases reported by our team do not intend to describe a new technique, but rather to support UCSs as an

(D) Maria Lúcia Moleiro's ORCID is https://orcid.org/0000-0002-18075014.
Address for correspondence Maria Lúcia Moleiro, MD, Departamento de Medicina Feminina e Reprodutiva, Centro Materno-Infantil do Norte, Centro Hospitalar Universitário do Porto, Largo da Maternidade de Júlio Dinis, 4050-651 Porto, Portugal (e-mail: lucia.moleiro@gmail.com).

adequate option to treat postpartum hemorrhage due to uterine atony, always bearing in mind the characteristics of each situation and the specificities of each suture.

\section{Conflicts of Interest}

The authors have no conflicts of interest to declare.

\section{References}

1 B-Lynch C, Coker A, Lawal AH, Abu J, Cowen MJ. The B-Lynch surgical technique for the control of massive postpartum haemorrhage: an alternative to hysterectomy? Five cases reported. $\mathrm{Br}$ J Obstet Gynaecol 1997;104(03):372-375. Doi: 10.1111/j.14710528.1997.tb11471.x

2 Pereira A, Nunes F, Pedroso S, Saraiva J, Retto H, Meirinho M. Compressive uterine sutures to treat postpartum bleeding secondary to uterine atony. Obstet Gynecol 2005;106(03):569-572. Doi: 10.10 97/01.AOG.0000168434.28222.d3

3 Sathe NA, Likis FE, Young JL, Morgans A, Carlson-Bremer D, Andrews J. Procedures and uterine-sparing surgeries for managing postpartum hemorrhage: a systematic review. Obstet Gynecol Surv 2016; 71(02):99-113. Doi: 10.1097/OGX.0000000000000273

4 El Refaeey AEA, Abdelfattah H, Mosbah A, et al. Is early intervention using Mansoura-VV uterine compression sutures an effective procedure in the management of primary atonic postpartum hemorrhage?: a prospective study BMC Pregnancy Childbirth 2017;17(01):160. Doi: 10.1186/s12884-017-1349-x

5 Mohamed MA, Mohammed AH. Parallel vertical compression sutures to control bleeding in cases of placenta previa and accreta. J Matern Fetal Neonatal Med 2019;32(04):641-645. Doi: 10.1080/ 14767058.2017.1387895

6 Şahin H, Soylu Karapınar O, Şahin EA, Dolapçığlu K, Baloğlu A. The effectiveness of the double B-lynch suture as a modification in the treatment of intractable postpartum haemorrhage. J Obstet Gynaecol 2018;38(06):796-799. Doi: 10.1080/01443615.2017.1420046

7 Mallappa Saroja CS, Nankani A, El-Hamamy E. Uterine compression sutures, an update: review of efficacy, safety and complications of B-Lynch suture and other uterine compression techniques 
for postpartum haemorrhage. Arch Gynecol Obstet 2010;281(04): 581-588. Doi: 10.1007/s00404-009-1249-Z

8 Kayem G, Kurinczuk JJ, Alfirevic Z, Spark P, Brocklehurst P, Knight M; U.K. Obstetric Surveillance System (UKOSS). Uterine compression sutures for the management of severe postpartum hemorrhage. Obstet Gynecol 2011;117(01):14-20. Doi: 10.1097/AOG 0b013e318202c596

9 Palacios-Jaraquemada JM. Efficacy of surgical techniques to control obstetric hemorrhage: analysis of 539 cases. Acta Obstet Gynecol Scand 2011;90(09):1036-1042. Doi: 10.1111/j.16000412.2011.01176.x

10 Doumouchtsis SK, Papageorghiou AT, Arulkumaran S. Systematic review of conservative management of postpartum hemorrhage: what to do when medical treatment fails. Obstet Gynecol Surv 2007;62(08):540-547. Doi: 10.1097/01.ogx.000 0271137. 81361.93

11 Gizzo S, Saccardi C, Patrelli TS, et al. Fertility rate and subsequent pregnancy outcomes after conservative surgical techniques in postpartum hemorrhage: 15 years of literature. Fertil Steril 2013;99(07):2097-2107. Doi: 10.1016/j.fertnstert.2013. 02.013

12 Cekmez Y, Ozkaya E, Öcal FD, Küçüközkan T. Experience with different techniques for the management of postpartum hemorrhage due to uterine atony: compression sutures, artery ligation and Bakri balloon. Ir J Med Sci 2015;184(02):399-402. Doi: 10.1007/s11845-014-1130-3 